\title{
Priming of new associations in reading time: What is learned?
}

\author{
RUSSELL A. POLDRACK and NEAL J. COHEN \\ University of Illinois at Urbana-Champaign, Urbana, Illinois
}

\begin{abstract}
The priming of new associations has been a controversial topic, with some studies finding significant effects but others failing to replicate these results. Three studies investigated the priming of new associations in a reading time task, presenting lists of word pairs that were read aloud as quickly as possible. In Experiment 1, significant priming of new associations was found after two study presentations, replicating similar results by Moscovitch, Winocur, and MacLachan (1986). In Experiment 2, reading time was facilitated for intact pairs when word positions remained constant relative to when word positions were reversed. This suggested that the associative priming effect was related to specific lower level features of the word pairs rather than to abstract associations. In Experiment 3 , the insertion of the word and between test words eliminated the pairing-specific effect, placing the locus of new association priming at the transition between words within pairs. These findings demonstrate that the knowledge that supports priming of new associations in the reading time task involves perceptual or articulatory information about the transitions between words rather than abstract associative knowledge.
\end{abstract}

A central question in the study of implicit memory phenomena has been the degree to which priming can occur for new memory representations. One approach to this question has been to examine priming for novel stimuli, such as nonsense objects (Schacter, Cooper, \& Treadwell, 1993) or visual patterns (N. J. Cohen, Abrams, Harley, Tabor, \& Sejnowski, 1986; Gabrieli, Milberg, Keane, \& Corkin, 1990). Most studies have successfully demonstrated priming for novel stimuli. Another approach has focused on whether implicit memory phenomena include priming of arbitrarily paired items, constituting memory for new relationships (or new associations) between preexisting representations. This "new association priming" is tested by presenting normatively unrelated stimuli in a paired manner at study and then testing whether performance is enhanced when studied pairs are presented at test compared with changed pairs of studied words. Both previously studied pairs and changed pairs would benefit from the repetition between study and test of the individual items. Any additional advantage for the previously studied pairs over the changed pairs would reflect memory for the study-time pairing.

The research presented here was supported by a predoctoral NRSA fellowship from NIMH to R.A.P. and by funds from the University of Illinois Research Board and Beckman Institute to N.J.C. The authors would like to thank Rob Althoff, Barbara Church, Gary Dell, Gordon Logan, Greg Murphy, and Scott Selco for their helpful discussions of this research, and Anthony Wagner and Dan Schacter for comments on previous versions of this paper. Correspondence should be addressed to R. A. Poldrack, who is now at Department of Psychology, Stanford University, Jordan Hall, Stanford, CA 94305 (e-mail: poldrack@psych.stanford.edu), or to N. J. Cohen, Amnesia Research Lab, Beckman Institute, University of Illinois, 405 N. Mathews, Urbana, IL 61801 (e-mail; njc@uiuc.edu).
There has been a great deal of controversy about whether or not priming of new associations occurs and what its representational basis might be. Because explicit remembering may contaminate implicit memory measures in normal subjects, the debate has centered on whether priming of new associations occurs in amnesic patients. Graf and Schacter (1985) first demonstrated priming of new associations in both normal and amnesic subjects using a paired word stem completion task. However, a subsequent study (Schacter \& Graf, 1986) noted that this effect occurred only for mildly amnesic subjects. Further studies (Mayes \& Gooding, 1989; Shimamura \& Squire, 1989) confirmed that associative priming is impaired in severe amnesics and showed that the priming effect was correlated with residual ability for explicit remembering in the amnesic patients (Shimamura \& Squire, 1989). Other evidence for the priming of new associations has come from a study by Moscovitch, Winocur, and McLachan (1986), which used reading time as a measure of performance. In this study, a set of memory-impaired patients and their controls exhibited normal reading time facilitation for intact word pairs compared with re-paired words (Experiment 3 ) after a single study presentation, while the patients showed impaired recognition for these word pairs. However, a subsequent set of studies by Musen and Squire (1993b) failed to replicate these results in both normal subjects and a set of well-characterized amnesic patients. Whereas Moscovitch et al. (1986) had found priming effects after a single study presentation, Musen and Squire (1993b) found that priming in both normal and amnesic subjects occurred only after 10 study presentations. These data appear to suggest that priming of new associations is qualitatively different from priming of single stimuli and that it depends on a slow, incremental learning mechanism. 
In addition to the priming of new associations found on reading time tasks, robust priming of new associations has been observed using other tasks. Musen and Squire (1993a) found priming of new associations in a version of the Stroop color-word task. Across study presentations, Stroop conflict stimuli (e.g., the word BLUE written in red ink) were presented with consistent colorword pairings, followed by transfer to a new set of colorword pairings. The results demonstrated pairing-specific naming time facilitation in both normal and amnesic subjects. Priming of new associations in a lexical decision task has been found by Goshen-Gottstein and Moscovitch (1995a, 1995b). They argued that this priming was perceptually based, because it was insensitive to levels of processing manipulations but was sensitive to changes in modality and presentation format. Finally, priming of new associations has also been found in a perceptual identification task in both normal and amnesic subjects (Gabrieli, Keane, Zarella, \& Poldrack, 1997). Together, these results demonstrate that priming of new associations can occur in some tasks, primarily on tests that are largely perceptual.

The experiments to be reported here examined the nature of new association priming in the reading time task. Facilitation in reading time as a function of prior experience is a well-known implicit memory phenomenon. The fact that amnesic patients exhibit normal priming in reading of whole paragraphs of text (Musen, Shimamura, \& Squire, 1990) suggests that this priming does not rely on declarative memory. Moscovitch et al. (1986) had originally interpreted their findings of pairing-specific effects as evidence for learning of experiment-time associations between words or concepts, which would not likely be supported by procedural memory mechanisms. However, the data do not compel this claim; other lower level information (such as word position information and phonological or articulatory information about word transitions) is confounded with abstract pairing information in their paradigm and related ones. Three experiments are reported here to explore this issue. The first was an operational replication of the Moscovitch et al. and Musen and Squire (1993b) studies. The second and third experiments examined in more detail the degree to which the memory representation supporting new association priming in the reading time task exhibits sensitivity to abstract pairing relationships versus more specific features involved in perceiving or articulating the paired stimuli. The manipulations in these experiments disrupted aspects of the production of word pairs without disrupting the abstract associations between pairs and, thus, examined the degree to which priming of new associations may inhere in the processes involved in speech production.

\section{GENERAL METHOD}

\section{Stimuli}

Eight lists of 20 word pairs were chosen for the experiment from the Francis and Kučera (1982) database. The lists were matched on the basis of word frequency $(M=51.16$, range $=48.7-53.7$ across lists $)$ and word length ( $M=6.59$, range $=6.45-6.7$ across lists $)$. The words were separated into associatively unrelated pairs; for each list, two nonoverlapping sets of pairings were created, keeping word position the same across the sets.

\section{Procedure}

Stimuli were presented using a Macintosh IIci computer with an Apple color monitor and were shown in black on a white background in a 24-point Times font. Words were presented in two columns whose left edges measured $5.5 \mathrm{~cm}$ apart. Millisecond timing accuracy was obtained using the VideoToolbox software package (Pelli, 1995).

Before the experiment, the subjects were instructed that they would be shown a list of 20 word pairs, and they were told that they should read the word list going across each pair and down the list as quickly and accurately as possible. They were also told that, if they made a mistake, they should continue reading the list without stopping or repeating the word. The subjects were given a break of approximately $3 \mathrm{sec}$ between the reading of each list. As in the experiments by Moscovitch et al. (1986) and Musen and Squire (1993b), reading time was measured from the onset of the word list until the subject read the last word on the list, at which point the experimenter pressed a button to stop the timer. The research assistants who served as experimenters for each experiment were informed of the general nature of the experiment (that word lists would be presented, that reading time would be measured, and that some lists would repeat during the experiment), but they were not given detailed information about the hypotheses of each experiment, in order to prevent any biases in recording the finishing times.

Each word list was presented three times consecutively, twice in its study form and once in a test form, for which the list could either be intact (unchanged from study) or changed. Each list was assigned to a given test condition (intact or changed) for each subject. The order of presentation for the word lists was determined using a Latin square design that ensured that each pairing set of each list appeared equally often in each test condition (intact vs. changed) at each serial position across subjects. On each list presentation, the order of word pairs within the list was randomized - that is, the only redundancy between the first and second readings was the word pairings, not the overall order of the list.

\section{Data analysis}

The primary dependent measure was reading time. Reading accuracy was not included in the analyses; Musen and Squire (1993b) found that the results of reading time analyses in a similar task did not differ depending on whether errors were taken into account. Given the difficulties in characterizing errors in the task, analysis was restricted to reading time. Statistical power analyses were performed using the G-Power package for the Macintosh (Buchner, Faul, \& Erdfelder, 1992) following procedures outlined in J. Cohen (1988).

\section{EXPERIMENT 1}

Experiment 1 was an operational replication of previous reading time studies (Moscovitch et al., 1986; Musen \& Squire, 1993b). For each of six word lists, the subjects received two study presentations of the list in which word pairings remained the same and then were presented with a test version of the list; for half of the lists, the word pairings were changed from the study presentation to the test presentation. In a similar experiment with one study presentation, Moscovitch et al. (Experiment 3 ) found that subjects were slowed when word pairings were changed. However, Musen and Squire failed to replicate this effect, only finding significant pairing-specific effects after 10 study presentations. Experiment 1 differed from the previous studies in the number of study presentations and 
Table 1

Reading Times (in Milliseconds) With Size of $95 \%$ Within-Subject

Confidence Interval (Loftus \& Masson, 1994) and Effect Sizes

(J. Cohen, 1988) for Experiments 1, 2, and 3

\begin{tabular}{|c|c|c|c|c|}
\hline \multirow{2}{*}{$\begin{array}{c}\text { Study } \\
\text { Presentation } 1\end{array}$} & \multirow{2}{*}{$\begin{array}{c}\text { Study } \\
\text { Presentation } 2\end{array}$} & \multicolumn{2}{|c|}{ Test } & \multirow[b]{2}{*}{ Effect Size $(d)$} \\
\hline & & Intact* & Changed $^{+}$ & \\
\hline & & Experiment 1 & & \\
\hline $21,852 \pm 290$ & $20,396 \pm 290$ & $19,457 \pm 276$ & $20,115 \pm 276$ & 1.005 \\
\hline & & Experiment 2 & & \\
\hline $21,047 \pm 257$ & $19,834 \pm 257$ & $19,028 \pm 287$ & $19,521 \pm 287$ & 0.727 \\
\hline & & Experiment 3 & & \\
\hline $21,730 \pm 229$ & $20,297 \pm 229$ & $21,087 \pm 278$ & $21,180 \pm 278$ & 0.140 \\
\hline
\end{tabular}

* For Experiment 1, intact pairing; for Experiment 2, intact position; for Experiment 3 , intact pairing (with and). ${ }^{\dagger}$ For Experiment 1, changed pairing; for Experiment 2, changed position; for Experiment 3, changed pairing (with and).

in a greater number of lists, allowing more power to find pairing-specific effects.

\section{Method \\ Subjects. Twenty-four undergraduate University of Illinois stu- dents participated in the experiment for course credit. All subjects were native speakers of English. \\ Procedure. The procedure followed the General Method outlined above. Half of the test lists were presented in their intact form (with original word pairings), and half were presented with changed pair- ings. For these changed lists, the alternate pairing set for that list (i.e., a different set from the study pairings) was presented. Across all sub- jects, each pairing set of each list occurred equally often as a study pairing and as a changed pairing.}

\section{Results and Discussion}

Reading time data for Experiment 1 are presented in Table 1. Reading time decreased significantly across the two study presentations. This was confirmed by a paired $t$ test between first and second study presentations $[t(23)=$ $7.39, p<.0001]$. This effect reflects a combination of word-specific and pairing-specific facilitation.

More importantly, there was a significant difference in reading time between intact-pairing lists and changedpairing lists on the test presentation $[t(23)=3.48, p<.01]$; reading times for changed-pairing lists were slower than those for intact-pairing lists in 16 of 24 subjects. This demonstrates that two study presentations were sufficient to establish priming of new associations. Reading time continued to improve for intact-pairing lists between the second and third presentation $[t(23)=6.12, p<.0001]$.

\section{EXPERIMENT 2}

The results of Experiment 1 suggested that the current procedure yields pairing-specific reading time effects after two study presentations, replicating Moscovitch et al. (1986). However, note that "pairing-specific" knowledge, in the sense of abstract relations between words, is confounded in this paradigm, as in previous work on reading time, with other information, such as word order within the pairs or lower level information (e.g., temporal associations between offset and onset phonemes in each word pair). Experiment 2 examined whether the pairing- specific knowledge found in Experiment 1 consisted of abstract (i.e., position-independent) pairing information or other more specific transition-related information. In this experiment, word order was changed within word pairs but word pairs werc kept intact. If the facilitation is based entirely on abstract word pairing information, then there should be no effect of changing word position (since word pairings remained the same from study to test for both intact-position and changed-position lists). If the facilitation is based on specific temporal or transitionbased features of the word pairs, then a position-specific effect should emerge.

\section{Method}

Subjects. Twenty-four undergraduate University of Illinois students participated in the experiment for course credit. All subjects were native speakers of English.

Procedure. The procedure followed the General Method outlined above. On the test presentation of each list, word pairs were presented either with the same word positions as during study (intact) or with the reversed word position (changed position); all word pairings remained the same during study and test.

\section{Results and Discussion}

Reading time results for Experiment 2 are presented in Table 1. As in Experiment 1, reading times decreased from the first to second study presentation $[t(23)=7.16$, $p<.0001]$, reflecting a combination of word-specific and pairing-specific learning.

There was a significant effect of changing the word position from study to test $[t(23)=2.48, p<.02]$; changedposition reading times were slower than intact-position reading times for 16 of 24 subjects. This result suggests that at least some portion of the learning that has previously been attributed to abstract knowledge about word pairs may in actuality be attributable to more specific features of the stimuli. As in Experiment 1, reading time continued to decrease for same-position lists between the second and third presentation $[t(23)=4.35, p<.0002]$.

In order to examine whether the position-specific effect was as large as the pairing-specific effect, the differences in reading time between same-position and changed-position lists were calculated for each subject in Experiments 1 and 2 as an index of the size of the pair- 
ing or position effect. There was no significant difference between the size of these effects across experiments $[t(46)=0.71, p>.47]$; however, this between-subjects test had relatively low power (power $=.52$ to find a "medium" effect), so it is unclear whether the position change was as large as the pairing effect.

Initial (Block 1) reading times were somewhat slower in Experiment 2 than in Experiment 1. The reason for this difference is unclear, since exactly the same word lists were used across experiments. However, this difference was not statistically significant $[t(46)=0.818, p>.41]$.

\section{EXPERIMENT 3}

Experiments 1 and 2 provided evidence that changes in word pairing or word position led to transfer effects on reading time and suggested that these effects may have been due to memory for features of the stimuli other than abstract knowledge about the word pairs. Experiment 3 further examined what knowledge subjects acquired by looking at the consequences of a manipulation that changed the production operations at test without changing the underlying word pairings. In this experiment, word pairings were changed at test for half of the lists, but, for all test lists (intact pairing and changed pairing), the word and was inserted between the paired words. If abstract knowledge about word pairings was responsible for facilitation for intact pairings in Experiment 1 , then the effect should persist despite the insertion of the word and. However, if the facilitation is specific to the phonological features of the stimuli or the articulatory operations used to produce them during study, then the difference between the reading times for intact or changed-pairing word lists seen in Experiments 1 and 2 should disappear, since the insertion of and between the words alters the transition sequence of the stimuli to be spoken.

\section{Method}

Subjects. Twenty-four undergraduate University of Illinois students participated in the experiment for course credit. All subjects were native speakers of English.

Procedure. The procedure followed that of Experiment 1 with one change. On each test list, the word and was inserted between the two paired words, and the subjects were told to read the and along with the paired words. The distance between the words in the pair remained the same during study and test.

\section{Results and Discussion}

Reading time data for Experiment 3 are presented in Table 1. As in Experiments 1 and 2, reading time decreased across the first two study presentations $[t(23)=$ $9.17, p<.0001]$.

Compared with Experiments 1 and 2, it is apparent that the insertion of the word and at test did result in some slowing for subjects in Experiment 3. Reading time for intact-pairing lists on the test reading was significantly slower than reading time for the same lists on the second study presentation $[t(23)=3.26, p<.01]$. However, the reading time for intact-pairing lists at test was still less than the initial reading time for the first study presentation $[t(23)=2.18, p<.04]$.

Most importantly, the insertion of and virtually eliminated any pairing-specific effect. There was no longer a significant effect of pairing changes $[t(23)=0.49, p>$ $.3]$, in contrast with the significant effects seen in Experiments 1 and 2; 12 of the 24 subjects exhibited slower reading times for changed-pairing lists than for intactpairing lists. The statistical power of this test to find an effect as large as the one in Experiment 1 was .96, and the power to find an effect as large as the one in Experiment 2 was 80 . This finding demonstrates that the pairingspecific effects observed in Experiment 1 depend crucially on the constancy of production operations from study to test and that the repetition of abstract information about word pairings independent of the form of the stimuli is not sufficient to facilitate reading time.

\section{GENERAL DISCUSSION}

Three experiments examined the nature of pairing-specific repetition priming in a reading time task with word pairs. Experiment 1 replicated previous findings of pairing-specific facilitation. Experiment 2 showed, however, that changes in word position that left word pairing intact also had significant effects on reading time, suggesting that the pairing-specific effects might not reflect abstract knowledge about the word pairs. Experiment 3 showed that changes in the production operations that were performed from study to test eliminated pairing-specific priming in the task, suggesting that the basis of this facilitation is tied to specific transition information.

The experiments presented here provided further evidence that priming of new associations in reading time can occur after few study presentations, replicating the positive finding of Moscovitch et al. (1986). In a similar study, Musen and Squire (1993b) failed to find any such priming except after 10 study presentations. One reason for this divergence of results might be experimental power; the present experiments used a greater number of longer word lists and, thus, had greater power to find new association priming. It is also possible that the second study presentation led to a significantly increased level of priming over the single presentation used by Musen and Squire (1993b). Finally, the nature of the subject groups may affect the findings; the subjects in the present experiments were university students, whereas the control subjects in the Musen and Squire (1993b) experiments were older adults. It is not clear at this point which of these factors is primarily involved; however, it is clear from the present experiments that new association proming does occur in the reading time task with only two study presentations.

\section{Perceptual Versus Production-Based Priming}

The results of the present experiments suggest that the pair-specific priming in speeded reading may not be at the level of abstract associations, as has sometimes been supposed (Moscovitch et al., 1986), but rather inheres in perceptual and/or production processes related to the specific sequence of the to-be-read stimuli. In suggesting that new association priming resides in the processes mediating reading performance, the present work parallels the proceduralist view of Kolers (see Kolers \& Roediger, 1984). In his well-known studies of mirror reading, Kolers showed that the amount of performance facilitation on a reading time test depended on the overlap of the pattern-analyzing procedures between study and test (e.g., Kolers \& Perkins, 1975). Just as Kolers rejected the idea that performance facilitation in the mirrorreading task reflects abstract knowledge about the words in the text (also see N. J. Cohen \& Squire, 1980), so the present results argue against abstract knowledge about word pairings underlying new association priming in speeded reading of plain text.

The present experiments do not allow us to determine whether these priming effects are based on perceptual representations or production- 
related representations, because each of the manipulations affected both perceptual and production processes. However, it could be argued on the basis of Experiment 3 that a production basis is more likely; the interposition of the word and between the paired words should not have severely affected the perceptual nature of the stimuli (since the word pairs remained in the same position as they had been during study) but should have drastically changed the nature of the production operations involved during the test trial. In this experiment, the imposition of and virtually eliminated the pairing-specific effect, suggesting that this effect may lie in the production operations involved during the reading aloud of the list.

Because speech production involves multiple processes (Levelt, 1989), it is not clear where in this stream the pairing-specific effect might occur. One likely candidate would be the process of phonological encoding. This is the process in which a lexical representation is translated into a phonological representation. Recent models of phonological encoding based on recurrent connectionist networks (e.g., Dell, Juliano, \& Govindjee, 1993) suggest that phonological encoding may involve learning mechanisms that acquire information about sequential redundancies in the speech stream, and this type of mechanism would naturally exhibit facilitation for repeated sequences of lexical markers and phonological features. Alternatively, the pairing-specific effects may arise from learning how to coarticulate a pair of words (i.e., learning how to program the musculature in order to most efficiently pronounce the words in sequence). Further research is necessary to disentangle these alternatives.

\section{Conclusions}

Three experiments examined word pair-specific priming in a reading time task. The results demonstrated robust new association priming that was highly specific to the processes involved during study, suggesting that this priming was supported by a facilitation of specific production operations rather than by priming of abstract lexical or semantic associations. The results extend the specificity of priming to the domain of new association priming and suggest that this type of priming may be based on the same procedural memory mechanisms as have been proposed for other examples of implicit memory phenomena (see N. J. Cohen \& Eichenbaum, 1993).

\section{REFERENCES}

Buchner, A., Faul, F., \& Erdfelder, E. (1992). G Power: A priori, post-hoc, and compromise power analyses for the Macintosh [Computer program]. Bonn: Bonn University.

COHEN, J. (1988). Statistical power analysis for the behavioral sciences. Hillsdale, NJ: Erlbaum.

Cohen, N. J., Abrams, I., Harley, W. A., Tabor, L., \& Sejnowski, T. (1986). Skill learning and repetition priming in symmetry detec tion: Parallel studies of human and connectionist models. In Proceedings of the Eighth Annual Conference of the Cognitive Science Society (pp. 23-44). Hillsdale, NJ: Erlbaum.

Cohen, N. J., \& Eichenbaum, H. (1993). Memory, amnesia, and the hippocampal system. Cambridge, MA: MIT Press.

CoHEN, N. J., \& SQuiRe, L. R. (1980). Preserved learning and retention of pattern-analyzing skill in amnesia: Dissociation of knowing how and knowing that. Science, 210, 207-210.

Dell, G. S., Juliano, C., \& Govindjee, A. (1993). Structure and content in language production: A theory of frame constraints in phonological speech errors. Cognitive Science, 17, 149-196.
Francis, W. N., \& Kučera, H. (1982). Frequency analysis of English usage: Lexicon and grammar. Boston: Houghton Mifflin.

Gabrieli, J. D. E., Keane, M. M., Zarella, M., \& Poldrack, R. A. (1997). Preservation of implicit memory for new associations in global amnesia. Psychological Science, 8, 326-329.

Gabrieli, J. D. [E.], MilberG, W., Keane, M. M., \& Corkin, S. (1990). Intact priming of patterns despite impaired memory. Neuropsychologia, 28, 417-427.

Goshen-Gottstein, Y., \& Moscovitch, M. (1995a). Repetition priming effects for newly formed associations are perceptually based: Evidence from shallow encoding and format specificity. Journal of Experimental Psychology: Learning, Memory, \& Cognition, 21, 1249-1262.

Goshen-GotTstein, Y., \& Moscovitch, M. (1995b). Repetition priming for newly formed and preexisting associations: Perceptual and conceptual influences. Journal of Experimental Psychology: Learning, Memory, \& Cognition, 21, 1229-1248.

GRAF, P., \& SCHACTER, D. L. (1985). Implicit and explicit memory for new associations in normal and amnesic subjects. Journal of Experimental Psychology: Learning, Memory, \& Cognition, 11, 501-518.

Kolers, P. A., \& PERKINs, D. N. (1975). Spatial and ordinal components of form perception and literacy. Cognitive Psychology, 7, 228-267.

Kolers, P. A., \& RoEdiger, H. L., III (1984). Procedures of mind. Journal of Verbal Learning \& Verbal Behavior, 7, 228-267.

LEVELT, W. J. M. (1989). Speaking: From intention to articulation. Cambridge, MA: MIT Press.

LoFTUS, G. R., \& MAsson, M. E. J. (1994). Using confidence intervals in within-subject designs. Psychonomic Bulletin \& Review, 1, 476-490.

MAYES, A. R., \& GoOdING, P. (1989). Enhancement of word completion priming in amnesics by cueing with previously novel associates. Neuropsychologia, 27, 1057-1072.

Moscovitch, M., Winocur, G., \& McLachan, D. (1986). Memory as assessed by recognition and reading time in normal and memoryimpaired people with Alzheimer's disease and other neurological disorders. Journal of Experimental Psychology: General, 115, 331-347.

Musen, G., Shimamura, A. P., \& Squire, L. R. (1990). Intact text-specific reading skill in amnesia. Journal of Experimental Psychology: Learning, Memory, \& Cognition, 16, 1068-1076.

MUSEN, G., \& SQuire, L. R. (1993a). Implicit learning of color-word associations using a Stroop paradigm. Journal of Experimental Psychology: Learning, Memory, \& Cognition, 19, 789-798.

MUSEN, G., \& SQUIRE, L. R. (1993b). On the implicit learning of novel associations by amnesic patients and normal subjects. Neuropsychology, 7, 119-135.

Pelli, D. G. (1995). VideoToolbox [Computer program]. Available http://rajsky.psych.nyu.edu/VideoToolbox/

Schacter, D. L., Cooper, L. A., \& Treadwel L, J. (1993). Preserved priming of novel objects across size transformation in amnesic patients. Psychological Science, 4, 331-335.

SChacter, D. L., \& Graf, P. (1986). Preserved learning in amnesic patients: Perspectives from research on direct priming. Journal of Clinical \& Experimental Neuropsychology, 8, 727-743.

Shimamura, A. P., \& Squire, L. R. (1989). Impaired priming of new associations in amnesia. Journal of Experimental Psychology: Learning, Memory, \& Cognition, 15, 721-728.

(Manuscript received November 25, 1996; revision accepted for publication March 12, 1997.) 